\title{
Glycemic Status, Lipid Profile and Proteinuria in Diabetic Nephropathy
}

\author{
Jha P, 'Das BKL,' Shrestha S, Majhi S, Chandra L, Sharma S, ${ }^{2}$ Baral N' \\ 'Department of Biochemistry, ${ }^{2}$ Department of Internal Medicine, BP Koirala Institute of Health Sciences, Dharan, Nepal.
}

\section{ABSTRACT}

Introduction: Diabetic nephropathy is one of the major complications of Diabetes Mellitus characterized by persistent albuminuria, elevated arterial blood pressure, a relentless decline in glomerular filtration rate (GFR) and a high risk of cardiovascular morbidity and mortality. ${ }^{1}$

Methods: In this study, urinary micro-albumin estimation was done in 177 diabetic patients. This study aims to ascertain association of glycemic status, lipid profile and proteinuria in Type 2 Diabetes Mellitus with nephropathy.

Results: Among 177 patients, 26 had frank proteinuria, 79 had micro-albuminuria and 72 were without proteinuria. Increased frequency of proteinuria was seen in male than female. Micro-albuminuria and frank proteinuria was seen more in older age group. The multiple comparisons showed the significantly increased levels of urea, creatinine, fasting blood glucose in micro-albuminuria and overt proteinuria patients in comparison to without proteinuria. Glycated hemoglobin level was increased with the increasing age group particularly in overt proteinuric patients.

Conclusions: The glycemic control, monitoring of lipid profile and early urinary protein estimation with better management may delay diabetic nephropathy or its further complications in diabetes mellitus.

Key Words: diabetes mellitus, diabetic nephropathy, frank proteinuria, glycated hemoglobin, micro-albuminuria

\author{
Correspondence: \\ Punam Jha \\ Department of Biochemistry \\ BP Koirala Institute of Health Sciences \\ Dharan, Nepal. \\ Email: punamiha@yahoo.com \\ Phone: 9842051893
}




\section{INTRODUCTION}

Diabetic nephropathy is one of the major complications of Diabetes Mellitus characterized by persistent albuminuria, elevated arterial blood pressure, a relentless decline in glomerular filtration rate and a high risk of cardiovascular morbidity and mortality. ${ }^{1,2}$

Strict control of hyperglycemia lowers the risk of nephropathy and of other diabetic complications in Type 1 Diabetes Mellitus. ${ }^{3}$ The decline in renal function over the time has been associated between initial glomerular filtration rate, initial urinary albumin excretion rate (UAE), hyperglycemia and age. ${ }^{4}$ Recent studies have demonstrated that the presence of proteinuria in Type 2 Diabetic patients increases the risk of cardiovascular death three to four times, independent of other risk factors.

Oxidized LDL-c particle may confer increased atherogenecity by virtue of their intrinsic physiochemical and metabolic properties including reduced LDL receptor affinity, greater propensity for transport into the subendothelial space, increased affinity for binding to arterial wall proteoglycans and susceptibility to oxidative modification. ${ }^{5-6}$

\section{METHODS}

This was a cross-sectional study done in Department of Biochemistry at B. P. Koirala Institute of Health Sciences, Dharan, from January 2006 to December 2006. One hundred and seventy-seven patients diagnosed with diabetic nephropathy were recruited randomly in this study after taking informed consent. Patients with hypertension, infection, heart failure and renal failure were not included in this study. After a 12-hour fast, $5 \mathrm{ml}$ of venous blood was collected of which about $4 \mathrm{ml}$ was kept in plain glass tubes and $1 \mathrm{ml}$ in EDTA (ethylenediaminetetraacetic acid) vial. Blood contained in glass tube was allowed to clot for 30-60 minutes. Serum was separated by centrifuging (Remi Research centrifuge model R-23) at 2500 rpm for 15 minutes at room temperature and stored at $-20 \mathrm{C}$ till the estimation. Quality control serum was run with each batch of samples to be tested. All the parameters of lipid profile (except HDL-c), both fasting blood glucose (FBG) and two hour post prandial blood glucose (PPBG), urea and creatinine were assayed by enzymatic kit methods in Merck Vitalab Selectra 2 Clinical Chemistry Autoanalyzer. Levels of total cholesterol and TG were determined by the colorimetric enzymatic methods. Levels of HDL-c were determined using phosphotungstic method. For the estimation of glycated hemoglobin ( $\mathrm{HbA} 1 \mathrm{c})$ the blood collected in the EDTA vial was used and assayed manually by resin-exchange method. Lipid values were classified according to the National Cholesterol Education Program
(NCEP) guidelines. ${ }^{7}$ The patients were divided into three groups based on pattern of protein in urine. The urine protein in all patients was measured by immunoturbidimetric method.

Data were analysed by using SPSS version 10.0. Data have been presented as Mean standard deviation and $\mathrm{P}<0.05$ was considered to be significant.

\section{RESULTS}

Of the total 177 diabetic patients included in this study $99(56 \%)$ of them were male and $78(44 \%)$ were female. Out of the 99 male patients, 34 were without proteinuria $(<30 \mathrm{mg} / \mathrm{d}), 48 \mathrm{had}$ micro-albuminuria $(30-300 \mathrm{mg} / \mathrm{d})$ and 17 had overt proteinuria ( $>300 \mathrm{mg} / \mathrm{d}$ ). Among the 78 female patients, 38 were without proteinuria, 31 had micro-albuminuria and 9 had overt proteinuria (Table 1). Among both male and female patients, of the total 177 patients, $72(41 \%)$ were without proteinuria, 79 (44\%) had micro-albuminuria and $26(15 \%)$ had overt proteinuria (Table 2).

Table 1. Sex wise distribution of different grades of proteinuria

\begin{tabular}{llll}
\hline & $\begin{array}{l}\text { Without proteinuria } \\
(30 \mathrm{mg} / \mathrm{d})\end{array}$ & $\begin{array}{l}\text { Microalbuminuria } \\
(30-300 \mathrm{mg} / \mathrm{d})\end{array}$ & $\begin{array}{l}\text { Overt proteinuria } \\
(>300 \mathrm{mg} / \mathrm{d})\end{array}$ \\
\hline $\begin{array}{l}\text { Male } \\
(\mathrm{n}=99)\end{array}$ & $34(34.34 \%)$ & $48(48.48 \%)$ & $17(17.17 \%)$ \\
$\begin{array}{l}\text { Female } \\
(\mathrm{n}=78)\end{array}$ & $38(48.72 \%)$ & $31(39.74 \%)$ & $9(11.54 \%)$
\end{tabular}

Table 2. Grades of Proteinuria in different age groups

\begin{tabular}{|c|c|c|c|c|}
\hline Age group & Without proteinuria & Mircro-albuminuria & Overt proteinuria & Total \\
\hline (in yrs) & $(<30 \mathrm{mg} / \mathrm{d})$ & $(30-300 \mathrm{mg} / \mathrm{d})$ & $(>300 \mathrm{mg} / \mathrm{d})$ & \\
\hline $30-45$ & $24(44.44 \%)$ & $26(48.15 \%)$ & $4(7.41 \%)$ & 54 \\
\hline $45-60$ & $37(48.05 \%)$ & $30(38.96 \%)$ & 10 (12.99\%) & 77 \\
\hline $60-75$ & $9(24.32 \%)$ & $20(54.05 \%)$ & $8(21.62 \%)$ & 37 \\
\hline$>75$ & $2(22.22 \%)$ & $3(33.33 \%)$ & $4(44.44 \%)$ & 9 \\
\hline Total & 72 (40.68\%) & 79 (44.63\%) & 26 ((14.69) & 177 \\
\hline
\end{tabular}

Mean value of fasting blood glucose was 13443.78 $\mathrm{mg} / \mathrm{dl}$ in normo-albuminuric group, $160.2252 .18 \mathrm{mg} / \mathrm{dl}$ in micro-albuminuric group and $154.2260 .13 \mathrm{mg} / \mathrm{dl}$ in overt proteinuric group and the difference between the normo-albuminuric and micro-albuminuric group was statistically significant $(P<0.05)$. Though there was difference in the mean values of post-prandial blood glucose value, the difference was not statistically significant. No statistically significant difference was seen in $\mathrm{HbA} 1 \mathrm{c}$ levels in the three groups of patients. The values of FBG, PPBG and $\mathrm{HbA} 1 \mathrm{c}$ in the patients reflect that they were under good glycemic control. 
Jha et al. Glycemic Status, Lipid Profile and Proteinuria in Diabetic Nephropathy

Biochemical parameters urea and creatinine done to assess the kidney function test were compared between the three patient groups (Table 3).

Table 3. Glycemic control in patients with different grades of proteinuria

\begin{tabular}{lccc}
\hline Parameters & Without proteinuria & Micro-albuminuria & Overt proteinuria \\
& $(<30 \mathrm{mg} / \mathrm{d})$ & $(30-300 \mathrm{mg} / \mathrm{d})$ & $(>300 \mathrm{mg} / \mathrm{d})$ \\
\hline FBG $(\mathrm{mg} / \mathrm{dl})$ & 13443.78 & $160.2252 .18^{*}$ & 154.2260 .13 \\
PPBG $(\mathrm{mg} / \mathrm{dl})$ & 222.6886 .59 & 242.2574 .29 & 243.47107 .34 \\
HbA1c $(\%)$ & 8.391 .62 & 8.521 .88 & 8.81 .73 \\
\hline
\end{tabular}

* significance between without proteinuria and microalbuminuria group $(P<0.05)$

The difference in values of urea as well as creatinine was statistically significant $(P<0.05)$ in micro-albuminuric and overt-proteinuric group when compared with withoutproteinuria group (Table 4). Lipid profile parameters in the three groups of patients when compared and of the four parameters only the difference in the triglyceride levels between the normo-albuminuric and overt proteinuric group was found to be statistically significant (Table 5) but not in cholesterol, HDL and LDL-c levels. Prevalence of nephropathy in this study was $59 \%$. The patients with micro-albuminuria were more in number than without proteinuria and overt proteinuria. The association between the risk of nephropathy and hyperglycemia was found to be non linear and continuous with or without a threshold value of glycated hemoglobin ( $\mathrm{HbA} 1 \mathrm{c})$

Table 4. Renal function tests in patients with different grades of Proteinuria

\begin{tabular}{lll}
\hline $\begin{array}{lll}\text { Parameters Without proteinuria Micro-albuminuria Overt proteinuria } \\
(<30 \mathrm{mg} / \mathrm{d})\end{array}$ & $\begin{array}{l}(30-300 \mathrm{mg} / \mathrm{d}) \\
(>300 \mathrm{mg} / \mathrm{d})\end{array}$ \\
\hline Urea(mg/dl) 225.81 & 25.1616 .99 & $37.2716 .66^{*}{ }^{+}$ \\
Creatinine 0.830 .23 & 1.101 .55 & $1.50 .78^{*,+}$ \\
(mg/dl) & & \\
\hline
\end{tabular}

"Significant difference between without proteinuria and overt proteinuria group $(P<0.05)$

${ }^{\dagger}$ Significant difference between micro-albuminuria and overt proteinuria group $(\mathrm{P}<0.05)$

\section{Table 5. Lipid profile in patients with different grades of proteinuria}

\begin{tabular}{llll}
\hline Parameters & $\begin{array}{l}\text { Without proteinuria } \\
(<30 \mathrm{mg} / \mathrm{d})\end{array}$ & $\begin{array}{l}\text { Micro-albuminuria } \\
(30-300 \mathrm{mg} / \mathrm{d})\end{array}$ & $\begin{array}{l}\text { Overt proteinuria } \\
(>300 \mathrm{mg} / \mathrm{d})\end{array}$ \\
\hline Cholesterol $(\mathrm{mg} / \mathrm{dl})$ & 172.8144 .09 & 175.9843 .59 & 188.0955 .15 \\
HDL-C $(\mathrm{mg} / \mathrm{dl})$ & 46.064 .52 & 43.407 .70 & 42.6611 .12 \\
TG $(\mathrm{mg} / \mathrm{dl})$ & 165.6259 .43 & 176.7749 .21 & $181.04422 .47^{*}$ \\
LDL-C $(\mathrm{mg} / \mathrm{dl})$ & 91.3227 .78 & 96.9834 .79 & 107.2350 .61
\end{tabular}

* Significant difference between without proteinuria and overt proteinuria group $(P<0.05)$

\section{DISCUSSION}

In this study, there was high prevalence of nephropathy in diabetic patients (59\%). Among the 177 diabetic patients, 72 patients were normo-albuminuric, 79 were micro-albuminuric and 26 were overtly proteinuric. Micro-albuminuria is a predictor of large vessel disease. Its prevalence varies in patients with diabetes from 7.6 to $42 \% .^{8.9}$ The frequency of diabetic nephropathy was more in male patients than female but the difference was statistically significant. Of the total 177 diabetic patients, most of them were in the micro-albuminuric group $(n=79)$ followed by normo-albuminuric group $(n=72)$ and the least number of patients were in the frank proteinuric group $(n=26)$. The association with the duration of diabetes has been found to be controversial, with studies showing micro-albuminuria in recently diagnosed patients. ${ }^{10}$ In this study it was found that though the maximum number of patients were in the age group of 45-60, the maximum frequency of overt proteinuria was seen in the patients in the age group of more than 75 years which could be due to long standing diabetes and poor glycemic control.
Fasting blood sugar was higher in micro-albuminuric group in comparison to normo-albuminuric and overt proteinuric group and the difference was statistically significant between microalbuminuric when compared with normoalbuminuric group. Glycated hemoglobin values were highest in overt proteinuric group followed by micro-albuminuric and normo-albuminuric group which could be due to the longer duration of diabetes. GFR correlates positively with $\mathrm{HbA} 1 \mathrm{c}$ in patients with incipient nephropathy. $\mathrm{HbA} 1 \mathrm{c}$ is regarded as the gold standard for measurement of glycemic control and is important for long term management of diabetic patients. It is also a predictor of diabetic complications as measures reducing $\mathrm{HbA} 1 \mathrm{c}$ correspondingly reduce the risk of complications. ${ }^{11}$ The rate of progression of nephropathy is correlated with metabolic control. In this study, as expected $\mathrm{HbA} 1 \mathrm{c}$ is highest in overt proteinuria patients than in microalbuminuria as well as in without proteinuric patients. 
The prevalence of hyper triglyceridemia and low HDL-c levels seen in the present study is similar to the reports by other workers. ${ }^{12-13}$ There was also a high prevalence of hypercholesterolemia and increased LDL-c levels which could be due to factors such as increased age of the subjects, increased consumption of saturated fat and cholesterol in the diet which was not assessed in our study, and the presence of genetic lipid disorders. As expected complication with diabetes, renal function was altered in this study. There was significant increase in urea and creatinine level in micro-albuminuric as well as in overt proteinuric groups in comparison to patients without proteinuria. This is because diabetes mellitus is one of the systemic diseases affecting the kidneys. Once micro-albuminuria is present, creatinine clearance declines at the rate that varies widely from patients to patients, on an average, reduction may be $10-12 \mathrm{ml} / \mathrm{min}$. ${ }^{14}$ Basement membrane thickening in diabetic nephropathy due to various factors affecting kidney function may be other cause for the raised urea and creatinine. Long standing diabetes affects the fasting blood glucose, post prandial blood glucose and glycated hemoglobin levels in Diabetes Mellitus patients. Glycated hemoglobin level was increased with the increasing age group which might be associated with the chronic complication of Diabetes. Lipid profile parameters were altered in the diabetic subjects and well correlated with the increased level of glycated hemoglobin. The cluster of lipid abnormalities associated with Type 2 Diabetes is defined by increase in Triglycerides (TG), small and dense Low Density Lipoprotein cholesterol (LDL-c) concentration and decrease in High Density Lipoprotein cholesterol (HDL-c). Direct atherogenic effects of TG rich particles, particularly Intermediate Density Lipoprotein (IDL) and remnant particles may account for the contribution of plasma TG levels to coronary heart disease risk. ${ }^{15}$ The association between the reduced HDLc levels and increased risk of heart disease is well established. HDL-c functions in cellular cholesterol efflux and has direct anti-oxidative as well as anti-inflammatory properties. Reduced HDL-c levels are often accompanied by elevated levels of plasma TG mediated by cholesteryl ester transport protein (CETP). ${ }^{16-17}$

\section{CONCLUSIONS}

The glycemic status along with the lipid profile values and early urinary protein estimation should be kept under strict control so that complications associated with diabetes would be delayed. The urinary protein excretion should be monitored regularly as it has been found to be associated with increased risk of cardiovascular diseases.

\section{REFERENCES}

1. Mogensen CE. Microalbuminuria predicts clinical proteinuria and early mortality in maturity onset diabetes. N Engl J Med. 1984;310:356-60.

2. Pugh JA, Medina R, Ramirez M. Comparison of the course to end stage renal disease of Type I and Type II Diabetic nephropathy. Diabetologica. 1993;36:1094-8.

3. The Diabetes Control and Complications Trial Research Group. The effect of intensive treatment of diabetes on the development and progression of long-term complications in insulin dependent diabetes mellitus. N Engl J Med.1993;329:977-86.

4. Pinho-Silveiro S, Friedman R, Gross JL. Glomerular hyperfiltration in NIDDM patients without overt proteinuria. Diabetes Care. 1993;16:115-9.

5. Fioretto P, Steffes MW, Brown DM, Mauer SM. An overview of renal pathology in insulin-dependent diabetes mellitus in relationship to altered glomerular hemodynamics. Am J Kidney Dis. 1992;20:549-58.

6. Brownlee M. Biochemistry and molecular cell biology of diabetic complications. Nature. 2001;414:813-20.

7. National Cholesterol Education Program. Third Report of the Expert Panel on Detection, Evaluation, and Treatment of High Blood Cholesterol in Adults (Adult Treatment Panel III). Bethesda: National Heart, Lung and Blood Institute; 2001.

8. Reichard P, Nilsson BY, Rosenqvist U. The effect of long term intensified insulin treatment on the development of microvascular complications of diabetes mellitus. N Engl J Med. 1993;329:304-9.

9. Chakrabarti S, Cukiernik M, Hileeto D, Evans T, Chen S. Role of vasoactive factors in the pathogenesis of early changes in diabetic retinopathy. Diabetes Metab Res Rev. 2000;16:393-407.
10. Bell ET. Renal disease. London: Henry Kimpton Publishers; 1946.

11. Baral N, Koner BC, Karki P, Ramaprasad C, Lamsal M and Koirala S. Evaluation of New WHO Diagnostic Criteria for Diabetes on the Prevalence of Abnormal Glucose Tolerance in a Heterogeneous Nepali Population - The Implications of Measuring Glycated Hemoglobin. Singapore Med J. 2000;41(6):264-7.

12. Koenig RJ, Peterson CM, Jones RL, Saudek C, Lehrman M, Cerami A. Correlation of glucose regulation and hemoglobin $\mathrm{A}_{1} \mathrm{C}$ in Diabetes Mellitus. N Engl J Med. 1976;295:417-20.

13. Taskinen MR. Diabetic dyslipidemia in NIDDM. International Diabetes Monitor. 1996;8:1-7.

14. UK Prospective Diabetes Study (UKPDS) group. Effect of intensive glucose control with Metformin on complication in overweight patients with Type 2 Diabetes. Lancet. 1998;352:85465.

15. Vigstrup J, Mogensen CE. Proliferative diabetic nephropathy: at risk patients identified by early detection of microalbuminuria. Acta Ophthalmol. 1985;63:530-4.

16. Mogensen CE. Microalbuminuria as a predictor of clinical diabetic nephropathy. Kidney Int. 1987;31:673-89.

17. Mogensen CE. Long term antihypertensive treatment inhibiting progression of diabetic nephropathy. BMJ. 1982;285:685-8. 